\title{
Measure of the Depression at Psychology Students
}

\author{
Basile Mulwani Makelele*, Christian Barhigenga Wewirhu \\ Department of Psychology, University of Lubumbashi, DR Congo \\ *Corresponding author
}

\begin{abstract}
Background: The University of Lubumbashi doesn't have the culture to evaluate the mental health and the humor's state of psychology's students who will be confronted with the multiple realities of the suffering patients with diverse psychiatric disorders, among whom in particular the disorders of the humor. Aims of the Study: The present study (i) measures the depression of students in psychology at University of Lubumbashi and (ii) analyzes the prevalence of gender and age to their depression. Instruments: Having made appeal to Beck Depression Inventory, we evaluate 60 first-year students of graduate in psychology who composing our sample, 30 women and 30 men from 18 to 23 years old. Results: It emerges from our investigations that $73.3 \%$ of students were depressive (5\% of grave Depression and 1.67\% of extreme Depression), with the depression's prevalence of men (80\%) and of less old students (75\%). Conclusion: The mental health of the students in psychology at University of Lubumbashi would thus be measured at least once during their academic program.
\end{abstract}

Keywords: depression, measure, psychology's student, beck depression inventory

Cite This Article: Basile Mulwani Makelele, and Christian Barhigenga Wewirhu, "Measure of the Depression at Psychology Students.” Research in Psychology and Behavioral Sciences, vol. 5, no. 1 (2017): 22-29. doi: 10.12691/rpbs-5-1-4.

\section{Introduction}

\subsection{Problematic}

The psychic background is a substantial holding in the actions and the futures reactions of everybody. It would thus be necessary to verify and to look after the psychic background of the students in psychology which one of their next missions will be look after the others.

The humor's state of future psychology's student should, normally, be measured from the entrance of this one to the studies in psychology. Indeed, they will be confronted during their internships with the suffering patients of various disorders, among whom those of the humor. They can, so, cause several problems, as those bound to the diagnosis and to the coverage, with doubtless an interference of their own disorders on those of patients.

The candidates for the studies in psychology would thus require, if possible, following a psychological consultation, before they are authorized to take care of others, specially, during their training courses of the end of cycle, professional training course, or simply during practical class in the course with psychopathological character.

At the University of Lubumbashi, the humor's state of psychology's students was never being the object of examination, and the learners evolve with their own psychological problems, without benefiting from any psychological help.

The depression is a very frequent disorder in many communities, essentially at the students. Besides, there are several studies led on the depression and associated disorders of the medical students since 1956 [1-8].
From the point of view emotional state, the medical students look like their counterparts of the other domains [1]. From psychology to medicine, there is only a step, so it would be necessary to estimate the humor's state of students in psychology, because it is inconceivable that a psychologist ignores his psychological profile and his mental health with regard to different therapeutics services he would organize.

Kessler \& Gask [9] suggest to manage depression in primary care, cause People commonly present with physical symptoms, and anxiety and depression commonly occur alongside chronic physical health problems.

So, the University of Lubumbashi could organize psychotechnical tests to apprehend better the morbid personalities of Congolese students, with the aim of improving the quality of their formation. This can be possible in the moment of student's examinations once or twice an academic year.

That is why this study aims in:

a) measuring the depression of students in psychology at University of Lubumbashi;

b) analyzing the prevalence of gender and age in depression of psychology's students at University of Lubumbashi.

\subsection{What is Depression?}

The depression is a state of total allowance, disinterestedness and making guilty observed at a person who has just lost a valuable item. This object can be a close being, a body's organ, a material or immaterial good.

Depression is more than unhappiness: A person who is depressed will experience low mood, which is lower than simply being 'sad' or 'unhappy', and crucially is associated 
with difficulty in being able to function as effectively as is usual for them in their everyday life [10].

Depression is a disorder which is very frequent in most of the societies, especially among students. These causes refuse students from fantastic possibilities for success, career and an appealing upcoming [11].

Karen D. Rudolph [12] report that depression can be conceptualized and measured at several levels as a symptom (sad mood); a syndrome (a theoretically or empirically derived constellation of associated symptoms) and a clinical disorder (a set of symptoms that meet specific diagnostic criteria).

Santor, Gregus \& Welch [13] enlighten that depression scales in terms of the proportion of Mood symptoms (depressed mood and irritability); Behavioral symptoms: (suicide and anhedonia); Somatic symptoms (appetite disturbance, sleep disturbance, low energy, and psychomotor retardation or agitation); Cognitive symptoms (hopelessness and worthlessness); and Concentration symptoms (poor concentration and decision making).

One of the mental disorders, the most often diagnosed and for which there is a large number of empirically validated, at the same time biological and psychological treatments [14], depression is a serious mental health problem that carries significant personal and societal costs [12] and bringing a deep change in the perception of the patient and his circle of acquaintances [15].

Some manuals of psychiatric nosology, among which the Diagnostic and Statistical Manual of Mental Disorders (DSM), distinguish the severity of the depression in light depression, moderate depression and severe depression.
Aubry [16] gave some symptoms of depression which are clarified in the Table 1.

And in the present study, we consider the following diverse forms of depression:

1) A normal state of humor;

2) Mild disorders of humor;

3) A borderline case of depression;

4) A depression averages said the depression;

5) A grave depression;

6) An extreme depression.

\subsection{About the Beck Depression Inventory}

In 1918, Woodworth developed what is arguably the first published measure of depression. The Psychoneurotic Inventory operationalized the construct of neurasthenia, which consisted of a broad collection of depressive and anxiety symptoms [13].

If the first statistical data on the epidemiology of depression go back up in 1950 in the United States [17]; It was developed and published, between 1918 to 2006, 280 measuring instruments of the depression [13].

Many of the scales, such as Beck Depression Inventory (BDI), Hamilton Depression Rating Scale (HRSD) and Center for Epidemiologic Studies Depression scale (CESD) have certainly been used widely and are likely to be among the most frequently used measures of depression [13].

In the Table 2 below, we have repertory common scales used to measure depression by self and heteroadministration [18,19,20,21,22].

Table 1. Some forms of Depression

\begin{tabular}{ll}
\hline Form & Symptoms \\
\hline Light depression & Discouragement, reduction of morale, in brief depresses, pitied to be overwhelmed. \\
Moderate depression & Passivity, tiredness, insomnias, indifference, retreat on one excessive or irritability and aggressiveness. \\
Severe depression & $\begin{array}{l}\text { Intense moral pain, maximum exhaustion, lack of interests, tasteful loss, disgust of one, consternation or on the } \\
\text { contrary agitation instability, suicidal attempts. }\end{array}$ \\
\hline
\end{tabular}

Table 2. Some specific instruments measuring the depression

\begin{tabular}{|c|c|}
\hline Instrument & Authors, year \\
\hline Anxiety and Depression Diagram, HARD & M. Ferreri \& JC. Rufin, 1984 \\
\hline Bech-Rafaelsen Mania Rating Scale, BRMAS & P. Bech \& O. Rafaelsen, 1980 \\
\hline Beck Depression Inventory, BDI & A.T. Beck ${ }^{1}, 1961$ \\
\hline Carroll Rating Scale for depression, CRS & B.J. Carroll, M. Feinberg, P.E. Smouse et al., 1982 \\
\hline Children's Depression Inventory, CDI & Maria Kovacs, 1979 \\
\hline Hamilton Psychiatric Rating Scale for Depression, HAMD & Max Hamilton, 1967 \\
\hline Montgomery and Asberg Depression Rating Scale, MADRS & Stuart Montgomery \& Marie Åsberg, 1979 \\
\hline Multiscore Depression Inventory-Children, $M D I-C$ & David J. Berndt \& Charles F. Kaiser, 1986 \\
\hline QD2A depression scale of Pichot & P. Pichot, P. Boyer, C.B. Pull and al., 1984 \\
\hline Questionnaire Center for Epidemiologic Studies Depression scale, CES-D & Lenore Sawyer Radloff, 1977 \\
\hline Retardation rating scale for depression, ERD & Daniel Widlöcher, 1983 \\
\hline
\end{tabular}

${ }^{1}$ Aaron Temkin Beck (born July 18, 1921) is an American psychiatrist and professor at the University of Pennsylvania. He built several instruments of evaluation in which we have Beck Depression Inventory (BDI), Beck Hopelessness Scale, Beck Scale for Suicidal Ideation (BSS), Beck Anxiety Inventory (BAI) and Beck Youth. 
The Beck Depression Inventory [23] is one of the most widely used selfreport measures of depressive symptomatology across a variety of patient and nonpatient populations [24]. And from the entire population of published measures, the BDI is generally more representative of depression scales in general, differing only slightly in the proportion of items used to assess mood and cognitive symptoms [13].

The original BDI was developed as a clinician rating scale and published in 1961 by A. T. Beck, C. H. Ward, M. Mandelson, J. Mock \& J. Erbauch [24]; and the amended Beck Depression Inventory (BDI-II) reflects the diagnostic criteria for major depressive disorders that are described in the American Psychiatric Association's Diagnostic and Statistical Manual of Mental Disorders, Fourth Edition [25].

And the Beck Depression Inventory (BDI) is more a measure of general psychopathology than a specific measure of depression when applied to psychiatrically normal students [26,27].

The Beck Depression Inventory contains 21 items quoted according to a gradual scale from 0 to 3 . These items measure the emotional, cognitive, behavioral and somatic aspects of the depression [28].

Beck et al. [23] reported that studies of the internal consistency and stability of the instrument indicate a high degree of reliability (coefficient of $0.86 r$ Pearson and coefficient Spearnan-Brown of 0.93). Comparisons between the scores on the inventory and the clinical judgments by the diagnosticians indicated a high degree of validity (Pearson biserial $r 0.65$ and 0.67 ).

Beck Depression Inventory II are intended to assist clinicians in determining which adults admitted for a psychiatric crisis require a comprehensive depression assessment and provide insight into the severity of patients' depression [29].

The French version of Beck Depression Inventory was prepared and administered by Paul Bourque and Daniel Beaudette. This instrument presents an internal consistency (0.92) and a reliability - retest satisfactory [28].

Beck, Ward, Mendelson, Mock, and Erbaugh [23] designated 21 symptom-attitude that constructed the scale BDI, evaluating typical attitudes and signs of depression in different categories that we report below:

a) Mood

b) Pessimism

c) Sense of failure

d) Lack of satisfaction

e) Guilty feeling

f) Sense of punishment

g) Self-Hate

h) Self-accusations

i) Self-punitivelwishes

j) Crying spells

k) Irritability

l) Social withdrawal

m) Indecisiveness

n) Body image

o) Work inhibition

p) Sleep disturbance

q) Fatigability

r) Loss of appetite

s) Weight loss

t) Somatic preoccupation u) Loss of libido.

\subsection{The Humor's State at the Students}

Many studies were made on depression, and some of them used Beck Depression Inventory, in case of four studies which made request to the Beck Depression Inventory on the measure of the depression at students:

a) The prevalence rate of depression among non-athlete and female students of Esfahan university [11];

b) There was significant level of depression (46.85\%), anxiety (74.12\%) and stress (52.44\%) among first year medical students of Maharajah's institute of Medical Sciences at Vizianagaram [5];

c) Depression and anxiety were more frequently reported by female students, first-year students, students in a poor economic situation and those who were not satisfied with their medical education students of Bursa in Turkish [7];

d) $53 \%$ of the computer science students had higher rate of moderate depression, and $7 \%$ of them and severe depression, but only 4\% medical students underwent severe depression (students and non-medical students of Madinah in Saudi Arabia) [8].

The anxious and depressive symptoms affect a third of the students [30,31]. The student population deserves a particular attention. If certain indicators show good living conditions and a good health, other indicators give evidence of sufferings [32].

Thus, Karl Peltzer et al. [33] indicated that in Africa:

- Among Assiut University in 2004, Ibrahim, Kelly \& Glazebrook find 37\% of Egyptian students scored above the threshold for moderate depression;

- In 2006, Terasaki, Gelaye, Berhane, \& Williams discover that Awassa's Ethiopian university students showed $23.6 \%$ symptoms of depression;

- In 2008 at the University of Nigeria (Enugu campus), Aniebue \& Onyema conclude a prevalence of depression of 23.3\% among 262 medical students.

The high frequency of the symptoms suggestive of a physical and psychological ill-being (fatigue, sleeping disorders, difficulties in concentrating, sadness or depression) also is to be underlined especially as these symptoms were declared at the beginning of the year university [32].

Grebot \& Barumandzadeh [30] inform that the motives most often advanced were the sentimental conflicts (26\%), the difficulties school as the failure and the stress (26\%), the solitude, the anxiety and the ill-being (21\%) and the estrangement of the family unit.

Peltzer et al. [33] reported six categories of factors increasing the risk of depression in university students have been identified as follows: 1) sociodemographic factors such as older age or higher study year, female gender , lower socioeconomic status; 2) stressful and traumatic life events including life stressors, gender-based violence, witnessing parental violence, and posttraumatic stress disorder; 3) addictive behaviour including high level of alcohol consumption, smoking , and gambling; 4) other health risk behavior such as physical inactivity, overweight or obesity, HIV risk behavior, sleeping problems, nonfatal unintentional injury, and use of skin lightening products; 5) social variables including social support, religiosity and/or spirituality, low sense of control; and 6) poor academic performance. 


\section{Materials and Methods}

\subsection{Description of the Study Area}

This study was led in May 2015 with first-year students of graduate in psychology at the University of Lubumbashi who answered the questionnaire of Beck Depression Inventory.

The University of Lubumbashi (UNILU in acronym) is a public high school institution in the Democratic Republic of Congo. Localize in the city of Lubumbashi, it includes fifteen faculties and schools, counting the Faculty of Psychology and Education Sciences [34].

The city of Lubumbashi, with an area of $747 \mathrm{~km}^{2}$, is an important city of the Democratic Republic of Congo. Originally a mining town, then administrative, it has a tropical two-season climate (dry and rainy) [34].

Lubumbashi is a name originated from Lubumbashi River. That in Lamba, local language, Lubumbashi means: ulubumba (clay). The clay that women used to shape vases and pots (lubumba also means potter producing clay pots). And founded in 1910 by the Belgians under the name of "Elisabethville", the city was renamed Lubumbashi in 1965 [34].

Our study sample consists of 60 students, whose characteristics are represented in the Table 3 below

Table 3. Characteristics of the sample

\begin{tabular}{cccc}
\hline \multirow{2}{*}{ Variables } & Number & Percentage \\
\hline \multirow{2}{*}{ Genre } & Women & 30 & 50 \\
& Men & 30 & 50 \\
\hline \multirow{3}{*}{ Age (year) } & {$[22-23]$} & 11 & 18.33 \\
& {$[20-21]$} & 29 & 48.33 \\
& {$[18-19]$} & 20 & 33.33 \\
\hline
\end{tabular}

The characteristics of our sample, summarized in the Table 3 above, show that, from gender, an equal representation of men and women students (30) 50\% respectively; from age, the respondents are aged 18 to 23 in which we have 11 students aged 22-23years old (18.33\%), 29 aged 20-21 (48.33\%) and 20 students aged (33.33\%).

\subsection{Assessment Tool}

The harvest of the data was made by means of the psychotechnical said Beck Depression Inventory of Aaron Temkin Beck.

It is a multiple-choice questionnaire of 21 questions, serving to measure the severity of the clinical depression. His aimed populations are the Adults (from 18 years). It is a test to be crossed collectively or individually during 5 at 10 minutes [35].

\section{Results}

In the crossroads of our scientific investigations, we found several reports on humor's state of the students were revealed to us concerning a view of distribution results on Beck Depression Inventory, prevalence of gender and age on Beck Depression Inventory.

\subsection{Distribution of the Results of the Students with Regard to Their Depressive State}

Results regarding participants' responses on Beck Depression Inventory are summarized in Table 4 below.

Table 4. Distribution in Beck Depression Inventory

\begin{tabular}{lcc}
\hline Depressive state to BDI & f & \% \\
\hline Extreme depression & 1 & 1.67 \\
Grave depression & 3 & 5 \\
Dépression & 17 & 28.33 \\
Borderline case & 12 & 20 \\
Mild disorders of humor & 11 & 18.33 \\
Normal state of humor & 16 & 26.67 \\
\hline
\end{tabular}

As presented in the Table 4 above, $73.3 \%$ were diagnosed depressives against $26.7 \%$ of detected students' normal for the Beck Depression Inventory. Indeed, on 60 subjects establishing our sample, only $26.67 \%$ of students were detected normal for the test of Beck, $18.3 \%$ showed a mild disorder of the humor, $20 \%$ were diagnosed Borderline case, 28.3\% students showed Depression, 5\% students indicated grave Depression and 1.67\% showed extreme Depression.

\subsection{Prevalence of Gender and Age on Beck Depression Inventory}

Results regarding participants' responses on prevalence of gender in Beck Depression Inventory are summarized in Table 5 below.

Table 5. Distribution results by gender in Beck Depression Inventory

\begin{tabular}{lcccc}
\hline \multirow{2}{*}{ Depressive state } & \multicolumn{2}{c}{ Women } & \multicolumn{2}{c}{ Men } \\
\cline { 2 - 5 } & f & \% & f & \% \\
\hline Extreme depression & 0 & 0 & 1 & 3.33 \\
Grave depression & 1 & 3.33 & 2 & 6.67 \\
Depression & 6 & 20 & 11 & 36.67 \\
Borderline case & 6 & 20 & 6 & 20 \\
Mild disorders of humor & 7 & 23.33 & 4 & 13.33 \\
Normal state of humor & 10 & 33.33 & 6 & 20 \\
\hline
\end{tabular}

In reference to gender of the tested students, the Table 5 presents the following results:

- $33.33 \%$ of women and $20 \%$ of men have Normal humor's state;

- 23.33\% of women and $13.33 \%$ of men manifest Mild humor's disorders;

- An exæquo percentage (20\%) of women and men have Borderline case;

- $20 \%$ of women and $36.67 \%$ of men manifest Depression;

- $3.33 \%$ of women and $6.67 \%$ of men have Grave depression;

- Finally, for the Extreme depression, only the men appear with $3.33 \%$ there. 


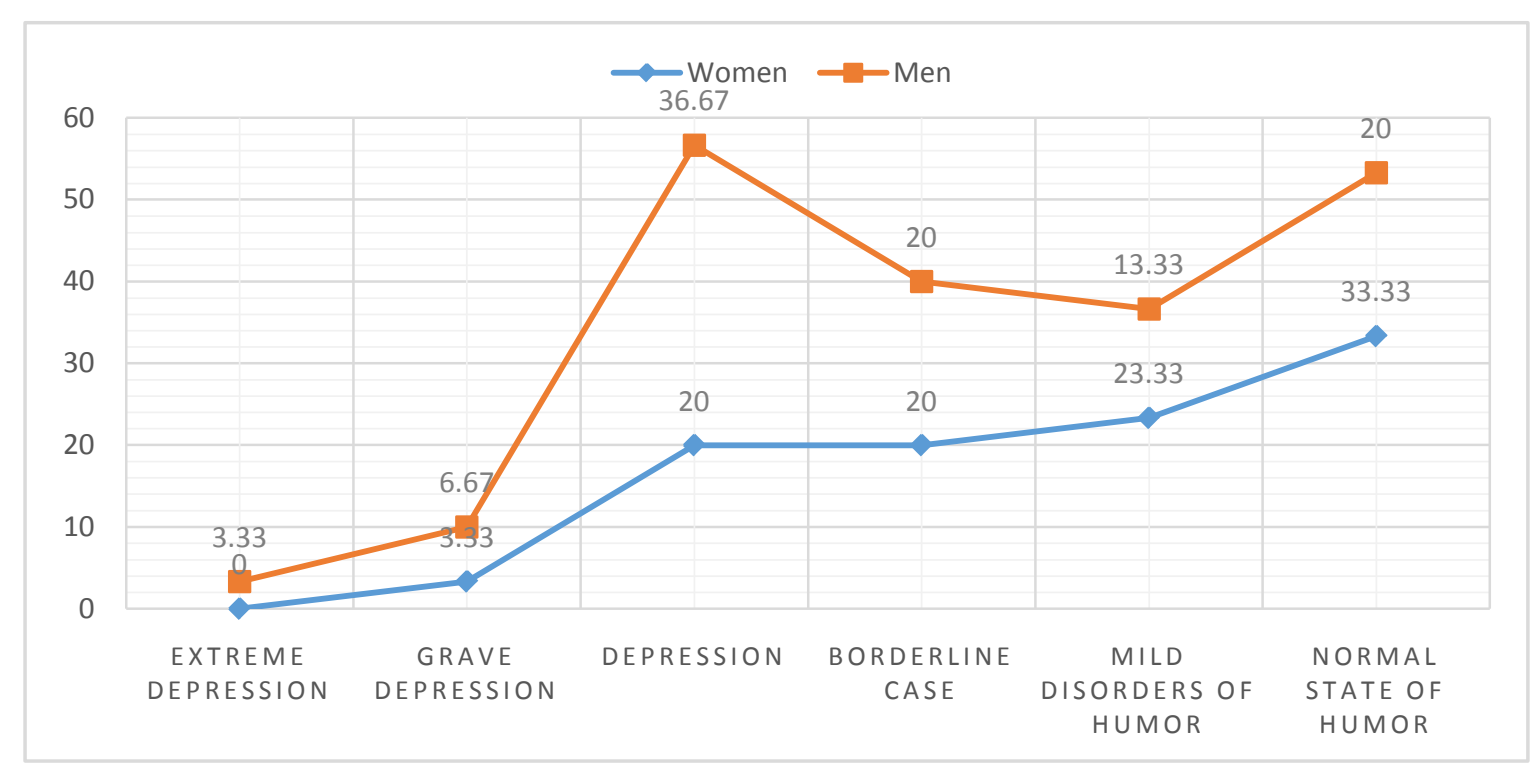

Figure 1. Distribution by genre of the results in Beck Depression Inventory

It emerges from this graph that the highest summit of two curves is indicated by the men subjects $(36.67 \%$ of depression), against a high summit of women's curve (33.33\% of normal).

Results regarding participants' responses on prevalence of age in Beck Depression Inventory are summarized in Table 6 below.

Table 6. Distribution results by age in Beck Depression Inventory

\begin{tabular}{lcccccc}
\hline \multirow{2}{*}{ Depressive state } & $\mathbf{1 8}$ to $\mathbf{1 9}$ ans & \multicolumn{2}{c}{$\mathbf{2 0}$ to $\mathbf{2 1}$ ans } & \multicolumn{2}{c}{$\mathbf{2 2}$ to $\mathbf{2 3}$ ans } \\
\cline { 2 - 7 } & $\mathbf{f}$ & $\mathbf{\%}$ & $\mathbf{f}$ & $\mathbf{\%}$ & $\mathbf{f}$ & $\mathbf{\%}$ \\
\hline Extreme depression & 0 & 0 & 0 & 0 & 1 & 9.09 \\
Grave depression & 1 & 5 & 0 & 0 & 2 & 18.18 \\
Depression & 7 & 35 & 9 & 31.03 & 1 & 9.09 \\
Borderline case & 5 & 25 & 5 & 17.24 & 2 & 18.18 \\
Mild disorders of humor & 2 & 10 & 9 & 31.03 & 0 & 0 \\
Normal state of humor & 5 & 25 & 6 & 20.69 & 5 & 45.45 \\
\hline
\end{tabular}

As regards the age of the examined students, the Table 6 established the following results:

- For Normal humor's state, we note $45.45 \%$ of 22-23-year-old subjects, $25 \%$ of those of 18-19 years and $20.69 \%$ of the 20-21-year-old subjects;

- The Mild disorders of the humor, it observes 31.03\% of students from $20-21$ years old and $10 \%$ of $18-19$ years;

- For the Borderline case, the results are $25 \%$ of $18-19$ year-old subjects, $18.18 \%$ of $22-23$ years and $17.24 \%$ of 20-21 years;

- As regards the Depression, we record 35\% of 18-19-year-old subjects, $31.03 \%$ of $20-21$ years and $9.09 \%$ of $22-23$ years;

- As for the Grave depression, it emerges $18.18 \%$ of 22-23 year-old students and 5\% of 18-19 years;

- And for the Extreme depression, only the 22-23 yearold appear with $9.99 \%$ are there.

So, $75 \%$ of students from 18 to 19 years old were detected depressives against $54.54 \%$ of those from 22 to 23 years.

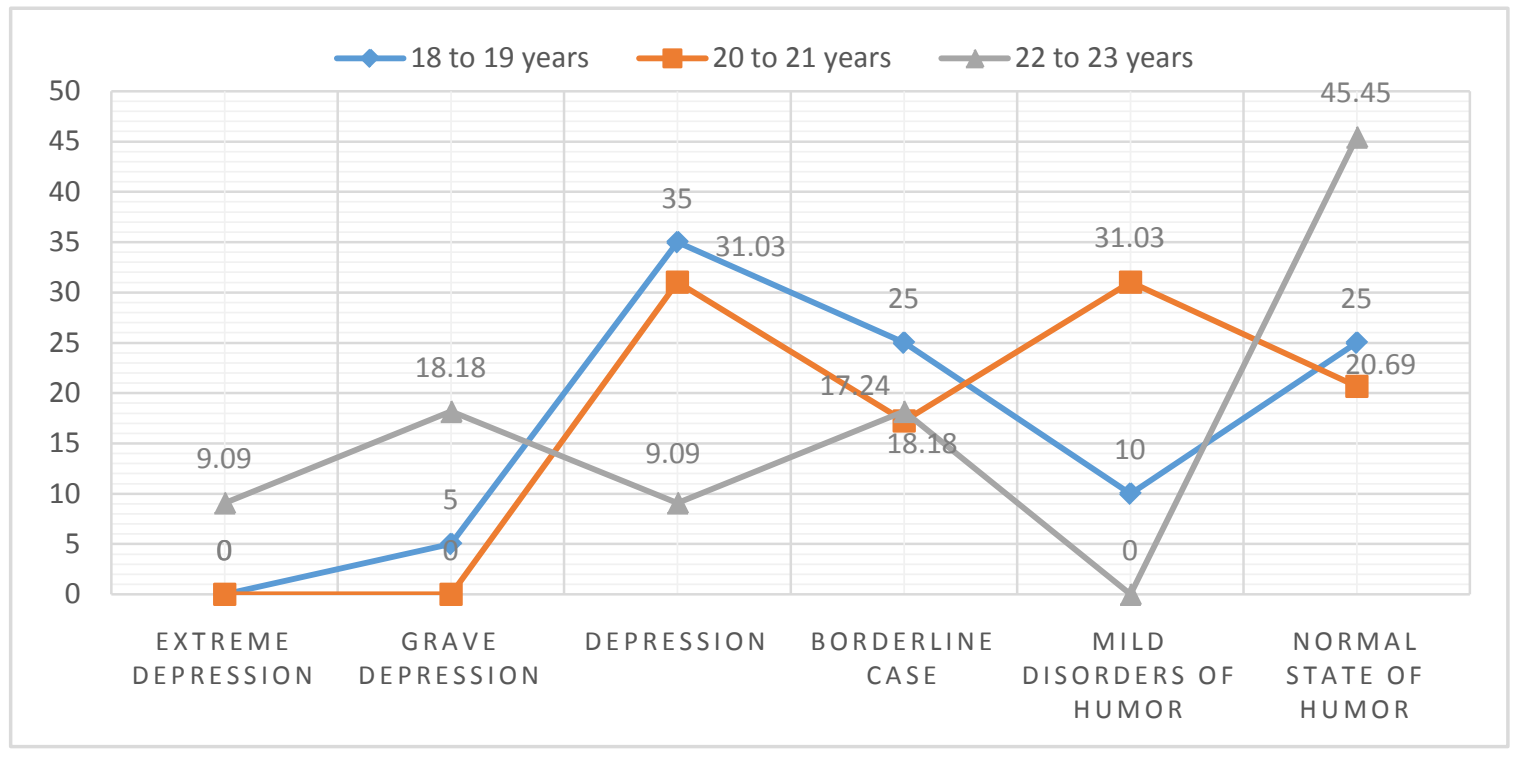

Figure 2. Distribution by aged of the results in Beck Depression Inventory 
He observes prevalence of the old normal subjects of 22-23 the years (45.45\%) against the less old subjects of $18-19$ the years (25\%) followed by the depression for 35\% of the old subjects of 20-21 the years.

\section{Discussion}

With regard to the results above presented, several information is given to us as regards the humor's state of psychology's student at University of Lubumbashi among which $73.3 \%$ were diagnosed depressives against $26.7 \%$ of normal detected students in Beck Depression Inventory.

On a different depressive picture of Lubumbashi, Tshilombo Ntalaja [36] had indicated hospitable prevalence of the depression (5.2\%) with regard to the other psychiatric pathologies of two hospital centers of Lubumbashi.

Regarding its prevalence, the World Health Organization estimated that nearly $15 \%$ of the global population on average suffered from depression, France and United States had, respectively $21 \%$ and $19.2 \%$, the highest rate of prevalence. And Ethiopia reported 9.1\% of depression's prevalence [37]; our study informs $73.3 \%$ of depressive students in psychology at University of Lubumbashi. So, about three quarter of students register in psychology are depressive. The situation seems thus chaotic, explicable and, however, debatable.

Another study made with Beck Depression Inventory concluded significantly higher depression among students of School of Health and Nutrition of Tabriz in Iran and showed that $62.7 \%$ of the students had depression and from these $10.9 \%$ suffered from severe depression [3] and 48.2\% au King Saud University de Riyadh, in Arabie saoudite by Al-Faris, et al. [38].

By these results, we understand the existence of an imminent need for psychological support of our future consultant psychologist before their permanent contact with the people whom they will convoy and take care.

The gender difference in depression remains significant across most depression diagnostic studies [39,40,41]. Women are considered as more depressive than men and it is often confirmed that the women are more subject to the depression

We found opposite results, because a large number of percentages of the students is characterized by the state of normal humor and the mild disorders of the humor, while the students find themselves numerous presenting morbid depressive states of depression, grave and extreme depression.

Only $33.33 \%$ of men students and $20 \%$ of women students were detected normal, while $80 \%$ of men students were detected depressives (among which 10\% of extreme and extreme Depression) against $66.67 \%$ of women (3.33\% of extreme Depression).

So, describing factors etiologics of the depression at the patients interned at the hospital Sendwe and at the neuropsychiatric center Joseph-Guislain of Lubumbashi, Tshilombo [36] found women ascendancy (58.8\%) with regard to men (41.2\%).

Gask \& Chew-Graham [10] prevent that estimates of prevalence vary considerably depending on the methods used to carry out the research, and the diagnostic criteria employed.
The observed greater prevalence of depression among women compared to men may be due to women having a greater number of first onsets, longer depressive episodes, a greater recurrence of depression than men, or all of these [39].

Indeed, Reda Abouserie observed that in academic situation, the indication of average stress was higher at the woman's than at the men. So, F. Michie, Mr Glachan and D. Bray observed that the men would be, on average, more confident than the women with regard to the autoperception of the appreciation of their academic skills by their peers [42].

In the general population women are more likely to be diagnosed with depression than men and major depression is found to be twice as common in females, as reported by many university studies [5,6,7,11,43].

Al-Busaidi, Bhargava et al. [44] showed no significant difference in the rate of depression between males and females among university students in Oman, which is contrary to the well-known notion that depression is more common in women in general.

So, although almost majority of studies on prevalence of the depression refer to the genre tilt to the genre women as being the most depressive, our discovery is whether they are the most depressive men, and not the women.

In the same subjects, Grant, Marsh et al. [45] noticed that the differences of gender of the rates of depressive disorder were found at male students and tended to decrease at the women student's.

Al-Qaisy [46] reports that some previous studies that investigated mental distress among university or college students using other survey methods and rating scales, and founded higher levels of depression among female students.

The University of Lubumbashi being one of the three big universities of the Democratic Republic of the Congo, it receives every year of thousands of students coming from other provinces, even other countries to pursue their university studies. Considering the cultural hazards in Africa, this travel of brains is more established by men than women.

To believe the existing links between the depression and the breakdown family as the statement in the studies previously evoked in this essay, some paths of answers can be thus given to us as for the ascendancy of the depression at the students that the students in this research. But still other studies have to be led on the etiology of the depression to the students in psychology.

Retrospective reports about age of onset in adult studies suggest that at least $50 \%$ of youngsters with major depression [47].

To believe other researches on the question, the depressive symptoms increase in a remarkable way from childhood to adolescence, both at the boys and at the girls [40].

Our results join the conclusion of all that the age influences the depression, because we found that only $25 \%$ of old students of $18-19$ years, $20.7 \%$ of $20-21$ years and $45.5 \%$ of $22-23$ years were detected normal, while $75 \%$ of students from $18-19$ years old, $79.2 \%$ of $20-21$ years and $54.58 \%$ of $22-23$ years were detected depressives.

For that purpose, our results join the words of Khawaja and Duncanson [43] which bring back that it is the 
younger and older age brackets which feel the higher rates of depression than the average age brackets.

Epidemiological studies have indicated that both younger and older age groups experiencing higher rates of depression than middle age groups [43].

\section{Conclusion}

Our study aims to be a plea for a psychological evaluation of every candidate in psychology studies to mitigate the possible problems of transfer to the treatment future of the psychological disorders to their patients.

Even if 73.3\% of Psychology students at the University of Lubumbashi were diagnosed depressives, only 5\% indicated grave Depression and $1.67 \%$ showed extreme Depression. We fund also the prevalence of gender and age on Beck Depression Inventory (80\% of men and $75 \%$ of less old students).

That's why, before entering to the University of Lubumbashi, every student has to cross the tests of physical and mental capacities, and nevertheless, only the tests of physical capacities are subjected to the candidate. No battery of personality tests or psychopathologics is administered and that make so incomplete the appreciation of the student's future.

It would be thus desirable that the mental health of the students of the University of Lubumbashi would be estimated at least once during their academic program. The state of mental health of the students of the faculty of psychology in particular, those the University of Lubumbashi generally has to be known and make question of a support before they are called to take care of others.

As such, it is proper to call back that the University of Lubumbashi has an appropriate frame of care of the students having of health problems as physical as mental: it is about private hospitals university of Lubumbashi. Nevertheless, we have to admit that this hospital frame enough indicated to serve as structure of support for the depressive students, any attention on the mental sphere of the students.

Set apart this report above presented, the City of Lubumbashi does not arrange enough official services of psychological consultation, seen that no official reference table of the psychologists who would work in the field of the mental health is not listed to Lubumbashi.

\section{References}

[1] Mehanna, Z. et Richa, S. (2006). "Prévalence des troubles anxiodépressifs chez les étudiants en médecine. Étude transversale chez les étudiants en médecine de l'Université Saint-Joseph de Beyrouth”. L'Encéphale, 32, pp.976-82, cahier 1.

[2] Sidana, S., Kishore, J., Ghosh, V., ... and Anand, T. (2012) "Prevalence of depression in students of a medical college in New Delhi: A cross-sectional study”. Australasian Medical Journal, 2012, 5, 5, pp.247-250.

[3] Safiri, S., Khanjani, N., Kusha, A., Narimani, M.R., Karamzad, N. (2013). "Prevalence of depression and its associated factors using Beck Depression Inventory among students of School of Health and Nutrition, Tabriz, Iran in 2009". Journal of Analytical R.

[4] Naidoo, S.S., Van Wyk, J., Higgins-Opitz, S.B. and Moodley, K. (2014). "An evaluation of stress in medical students at a South African university”. South African Family Practice, 56(5), pp.1-5.
[5] Patnaik, K.K., Samuel, C.M., Pathrudu, G.B., ... and Bodhe, A.V.P. (2015). "Depression, anxiety \& stress among first year medical students: A cross sectional study”. Journal of Dental and Medical Sciences, Volume 14, Issue 10 Ver. VI, pp.25-28.

[6] Shim, E.J., Jeon, H.J., Kim, H., ... and Hahm, B.J. (2016). "Measuring stress in medical education: validation of the Korean version of the higher education stress inventory with medical students”. BMC Med Educ. 2016 Nov 24 ;16 (1), p.302.

[7] Ediz, B., Ozcakir, A. and Bilgel, N. (2017). "Depression and anxiety among medical students: Examining scores of the beck depression and anxiety inventory and the depression anxiety and stress scale with student characteristics”. Cogent Psychology, 4.

[8] Al Raddadi, W., Aljabri, J. N., Kareem, M. A., Alattas, A. M. and Alkhalawi, M. J. (2017). "The Prevalence of Depression and Anxiety among Medical Students in Comparison with NonMedical Students: A Cross-Sectional Study in Taibah University, Al Madinah A.

[9] Kessler, D. and Gask, L. (2014). "Chapter 3: Anxiety and Depression in Adults”. In ABC of anxiety and depression, Edition John Wiley \& Sons, Ltd.

[10] Gask, L. and Chew-Graham, C. (2014). "Chapter 1: Introduction: Anxiety and Depression”. In ABC of anxiety and depression, Edition John Wiley \& Sons, Ltd.

[11] Ghaedi, L. and Mohd Kosnin, A. B. (2014). "Prevalence of Depression among Undergraduate Students: Gender and Age Differences”. International Journal of Psychological Research, vol.7, N², pp. 38-50.

[12] Rudolph, K. D. (2009). “Adolescent Depression”. In Handbook of depression, Gotlib, I.H. et Hammen, C. L. (editors), Second Edition, the Guilford Press, New York, London, pp.444-466.

[13] Santor, D. A., Gregus, M. and Welch, A. (2006). "Eight Decades of Measurement in Depression”. Measurement, 4 (3), pp.135-155.

[14] Kramer, U., Belz, M. et Caspar, F. (2013). "U. Kramer, M. Belz, F. Caspar, Psychothérapie de la dépression chronique : l'apport du modèle CBASP selon McCullough", L’Encéphale, 39, pp.137-142.

[15] Gotlib, I. H. and Joormann, J. (2010). "Cognition and Depression: Current Status and Future Directions”. Annu Rev Clin Psychol., 6, pp.285-312.

[16] Aubry, C.-M. (2011). Les 7 clés pour vaincre déprime et dépression et profiter de la vie. Éditions Dangles.

[17] Kessler, RC. and Wang, P. S. (2009). "Epidemiology of Depression”. In Handbook of depression, Gotlib, I. H. et Hammen, C. L. (editors), Second Edition, the Guilford Press, New York, London, pp.5-22.

[18] Berndt, D. J. and Kaiser, C. F. (1986). "Multiscore Depression Inventory for Children". Manual, WPS.

[19] Cialdella, P. (1999). "Échelles d'évaluation de la psychopathologie. Texte revu de P. Hardy, D. Servant, Séminaire de formation du FUAG à Lyon.

[20] Da Fonseca, D., Cury F., Rufo, M. et Poinso, F. (2007). "Facteurs prédicateurs de la dépression chez l'adolescent en contexte scolaire : rôle des théories implicites de l'intelligence". L’Encéphale, N³3, pp.791-797.

[21] Ferreri, F. et Agboko, C. (2003). "Dépression et troubles de l'humeur”. Le généraliste, $\mathrm{N}^{\circ} 2266$.

[22] Guelfi, J.D. (2010). "Chapitre 17 : Psychopathologie quantitative et psychométrie de la dépression”. In les états dépressifs, Goudemand (dir.), Coll. Psychiatrie, pp.142-151.

[23] Beck, A.T., Ward, C.H., Mendelson, M., Mock, J. and Erbaugh, J. (1961). “An Inventory for Measuring Depression”. Archives of General Psychiatry, 4, pp.561-751.

[24] Nezu, A. M., Maguth Nezu, C., Friedman, J. and Lee, M. (2009). "Assessment of Depression”. In Handbook of depression, Gotlib, I.H. et Hammen, C.L. (editors), Second Edition, the Guilford Press, New York, London, pp.44-68.

[25] Steer, R. A., Ball, R. and Ranieri, W. F. (1999). "Dimensions of the Beck Depression Inventory-II in Clinically Depressed Outpatients". Journal of clinical psychology, Vol. 55(1), pp.117-128.

[26] Hill, A.B. and Kemp-Wheeler, S.M. (1986). "What does the Beck depression inventory measure in students?” Personality and Individual Differences, Volume 7, Issue 1, pp. 39-47. .

[27] Tashakkori, A., Barefoot, J. and Mehryar, AH. (1989). "What does the Beck Depression Inventory measure in college students? Evidence from a non-western culture”. Journal of Clinical Psychology, 45(4), pp.595-602. 
[28] Gosselin, M.-J. (1995). "Étude de la dépression chez les adolescents en regard de l'appréciation subjective de l'habileté de résolution de problèmes personnels et des événements de vie stressants”. Mémoire de maîtrise en psychologie, Université du Québe.

[29] Subica, A. M., Fowler, J. Christopher, Elhai, J. D., ... and Allen, J. G. (2014). "Factor Structure and Diagnostic Validity of the Beck Depression Inventory-II with Adult Clinical Inpatients: Comparison to a Gold-Standard Diagnostic Interview”. Psychologica.

[30] Grebot, E. et Barumandzadeh, T. (2005). “L’accès à l'Université : une situation stressante à l'origine de certaines stratégies d'ajustement dysfonctionnelles”. Annales Médico Psychologiques, 163, pp.561-567.

[31] Strenna, L., Chahraoui, K. et Vinay, A. (2009). "Santé psychique chez les étudiants de première année d'école supérieure de commerce : liens avec le stress de l'orientation professionnelle, l'estime de soi et le coping”, L'orientation scolaire et profes.

[32] Migeot, V., Ingrand, I., Defossez, G... et Ingrand, P. (2006) "Comportements de santé des étudiants d'IUT de l'Université de Poitiers”. Santé Publique, N² (Vol. 18), pp. 195-205.

[33] Peltzer, K., Pengpid, S., Olowu, S. et Olasupo, M. (2013). "Depression and Associated Factors Among University Students in Western Nigeria”. Journal of Psychology in Africa, 23(3), pp.459-466.

[34] Makelele, B. M., Libote, P. L., \& Kasas, B. A. A. (2017). A Study on the Perception of Congolese Students towards Sape. Research in Psychology and Behavioral Sciences, 5(1), 6-12.

[35] Makelele, B. M. (2017). "Psychopathologie Générale et Africaine”. Cours inédit de 3ème graduat en Psychologie, Université de Lubumbashi, Lubumbashi.

[36] Tshilombo Ntalaja, E. (2013). "Les facteurs étiologiques de la dépression à Lubumbashi. Cas de l'hôpital Sendwe et du centre neuropsychiatrique Joseph- Guislain de 2009 à 2012”. Mémoire présenté pour l'obtention du grade de docteur en médecine, Universi.

[37] Bitew, T. (2014). "Prevalence and risk factors of depression in Ethiopia: a review”. Ethiop J Health Sci. Vol. 24, $\mathrm{N}^{\circ} 2$
[38] Al-Faris, E.A., Irfan, F., Van Der Vleuten, C.P., ... and Alofaisan, Y. (2012). "The prevalence and correlates of depressive symptoms from an Arabian setting: A wake up call”. Medical teacher, 34, pp. S32-S36.

[39] Nolen-Hoeksema and S. Hilt, L. M. (2009). "Gender Differences in Depression”. In Handbook of depression, Gotlib, I.H. et Hammen, C.L. (editors), Second Edition, the Guilford Press, New York, London, pp.386-404.

[40] Eloirdi, A., Arfaoui, A. et Ahami, A.O.T. (2014). "Evaluation de l'impact de l'estime de soi et de l'état dépressif sur la performance sportive chez les jeunes adolescents scolarisés”. Antropo, 32, pp.25-34.

[41] Baldwin, D. and Birtwistle, J. (2002). An atlas of depression. The encyclopedia of visual medicine, Parthenon Publishing Group.

[42] Lisiecki, J. (2013). "Étude sur les déterminants sociaux de la détresse psychologique des étudiants universitaires canadiens". Mémoire présenté à la Faculté des études supérieures en vue de l'obtention du grade de Maître ès sciences en Sociologie, Unive.

[43] Khawaja, N. G. and Duncanson, K. (2008). "Using the University Student Depression Inventory to Investigate the Effect of Demographic Variables on Students' Depression”. Australian Journal of Guidance and Counselling, 18(2). pp. 1-15.

[44] Al-Busaidi, Z., Bhargava, K., Al-Ismaily, Aida ..., and Al-Maniri, A. (2011). "Prevalence of Depressive Symptoms among University Students in Oman”. Oman Medical Journal, Vol. 26, $\mathrm{N}^{\circ} 4$, pp.235-239.

[45] Grant, K., Marsh, P., Syniar, G.,... and Cowman, S. (2002). "Gender differences in rates of depression among undergraduates: measurement matters”. Journal of Adolescence, Volume 25, Issue 6, December 2002, Pages 613-617.

[46] Al-Qaisy, L. M. (2011). "The relation of depression and anxiety in academic achievement among group of university students". International Journal of Psychology and Counselling, Vol. 3(5), pp. 96-100.

[47] Kessler, RC., Avenevoli, S. and Ries Merikangas, K. (2001) "Mood disorders in children and adolescents: an epidemiologic perspective”. Biol Psychiatry, 49 (12), pp.1002-1014. 